\title{
MODELING OF SOLAR ASSISTED HEAT PUMPS COMBINED WITH PHOTOVOLTAIC THERMAL MODULES
}

\author{
Riccardo Simonetti, Luca Molinaroli and Giampaolo Manzolini \\ Department of Energy, Politecnico di Milano, Via Lambruschini 4, 20156 Milano, (Italy)
}

\begin{abstract}
This work summarizes the performance of a Solar Assisted Heat Pump integrating Photovoltaic thermal (PV/T) modules. This configuration reduces the disadvantage of low temperature heat recovery typical of PV/T modules as the fluid temperature is used to drive the heat pump evaporator instead of an end-user and, consequently, can be close to the ambient one. A detailed model featuring real components is developed in MATLAB ${ }^{\circledR}$ to correctly predict the SAHP performance as function of the design parameters (number of PV/T modules) and ambient conditions (solar irradiance and ambient temperature). In addition, an optimization tool was combined with the model to maximize the COP (Coefficient of Performance) by varying the water flow rate circulating in the PV/T panels. Results outline the benefits of this concept with respect to conventional air/water heat pumps in particular when the ambient temperature is below zero as the frost formation issue is not present. COP reaches high values, between 2.5 and 4.9 in the case with $12 \mathrm{PV} / \mathrm{T}$ panels and between 2.2 and 6.2 with 24 . Advantages in terms of electricity production are outlined as well, with an increasing of $8-9 \%$ of the power produced.
\end{abstract}

Keywords: Solar Assisted Heat Pumps, Photovoltaic Thermal modules.

\section{Introduction}

Photovoltaic thermal (PV/T) modules combine thermal and electricity production. The main drawback of this technology is the low thermal efficiency and stagnation temperature because of the high thermal losses (Aste, et al., 2014; Zondag, et al., 2003). Insulation systems like vacuum chamber or the adoption of concentrators can be considered but require the installation of auxiliary rejection systems to control the PV cell temperature when the heat demand is absent (Kumar, et al., 2015). Another option to exploit the PV/T potentiality without increasing the module complexity consists of their integration with a heat pump (HP) leading to the so-called solar-assisted heat pump (SAHP) concept: the heat recovered by the PV/T modules supplies the heat duty of the HP evaporator (Ji, et al., 2008). A detailed study over this system was conducted by (Nuntaphan, et al., 2009) that has experimental analyzed the performance of an indirect SAHP coupled with solar flat collectors including a hot water storage of $300 \mathrm{dm}^{3}$. Results demonstrate higher system efficiency with respect to traditional configurations (air/water HP or thermal panels), with a gain that reaches $40 \%$. (Li, et al., 2014) has analyzed an indirect SAHP with flat solar collectors for residential heating. The study was done with a model developed in TRNSYS and results demonstrated that $68.1 \%$ of the heating and domestic hot water demand was covered by the SAHP. Moreover, the performance is increased by $140 \%$ respect of a standard HP and the energy saving is close to $52 \%$. (Liu, et al., 2014) has investigated a system with a SAHP and vacuum solar collectors for residential use. An experimental set-up is used to validate a model built in TRNSYS. The study shows that, considering a system designed for a solar fraction of $20 \%$, about $66 \%$ of the thermal load can be covered in the worst month and it is possible to reduce the energy consumption by $55 \%$ with respect to a traditional layout with a boiler . (Calise, et al., 2016) has studied the performance of a three-generation system composed by an indirect SAHP integrating $\mathrm{PV} / \mathrm{T}$ solar panels for heating/cooling loads in a residential application. The model, developed in TRNSYS, shows that the system can cover the entire thermal load and the average performance is $30 \%$ higher than a standard HP. The SAHP configuration fixes the PV/T low stagnation temperature issue as the PV/T operating temperature can be close to the ambient one. In addition, the PV power output increases with respect to conventional PV module because of the PV cell cooling effect (Migliorini, et al., 2017). In this work, a detailed modeling of the SAHP concept is carried out to assess the system performance and power output as function of the ambient conditions (irradiance and ambient temperature) and the design specification (number of PV/T modules and thermal efficiency). Physical behavior of all the components of the system are completely characterized, heat transfer coefficients and pressure drops are determined using typical correlation referenced in literature and a solver for a 
system with non-linear equations is used. An optimization tool is also implemented to maximize the performance in each different ambient condition, varying the volumetric flow rate that flows in the PV/T panels. With this comprehensive tool, developed in $\mathrm{MATLAB}^{\circledR}$, it is possible to automatically obtain optimized performance maps for a variable number of $\mathrm{PV} / \mathrm{T}$ modules.

The paper is structured as follows. Section 2 describes the concept and the layout of the system studied. In Section 3 models of the components are explained. Section 4 presents the methodology proposed to define design condition and the optimization method used. In Section 5 main results of the paper are presented and discussed. Finally, in Section 6 conclusions are drawn.

\section{The Concept}

A schematic of the concept modelled in this work is reported in Fig. 1.

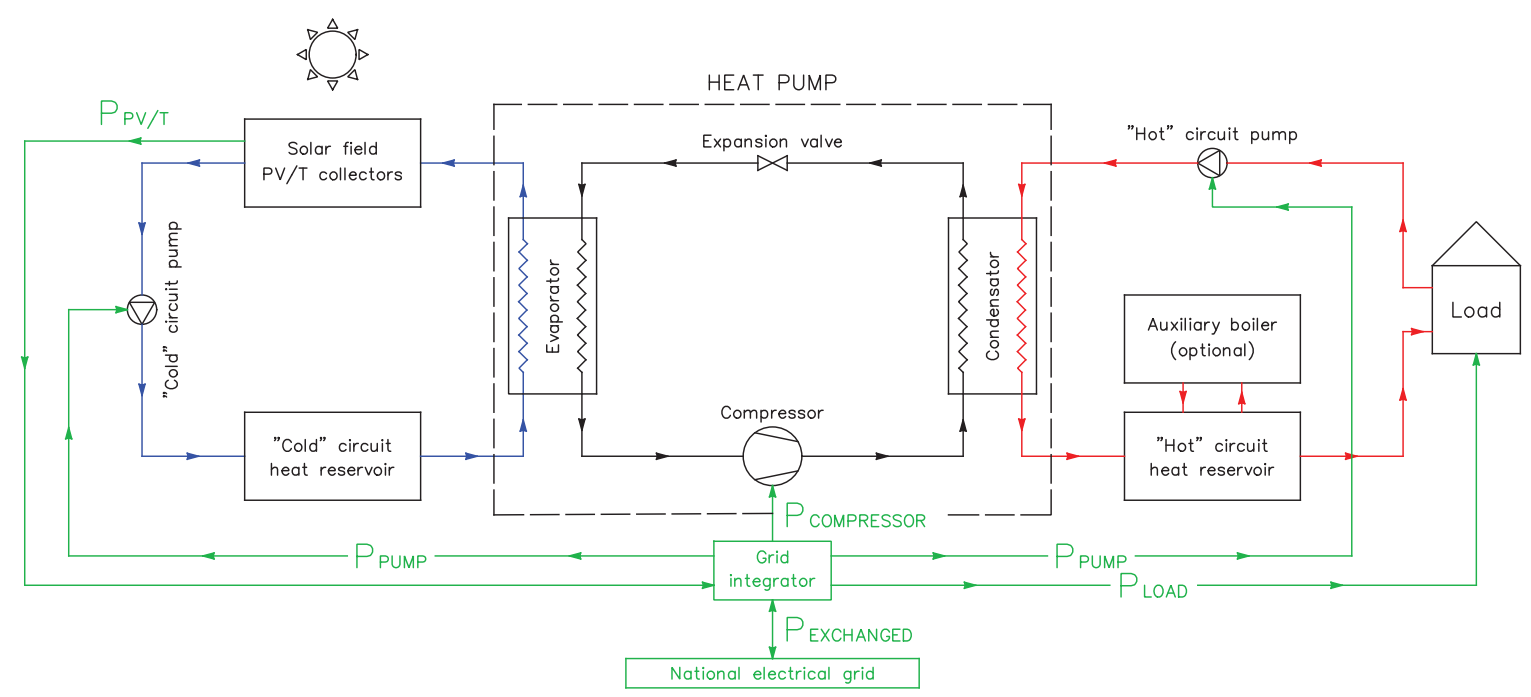

Fig. 1: Schematic of the system modelled in this work

The system consists of a water-to-water HP, PV/T modules and a thermal storage, being the latter component mandatory to decouple the solar energy availability with the thermal load. PV/T modules convert solar energy in thermal and electric ones: the first of them is used in the evaporator of the HP; the electric energy can be used to reduce/cover the HP electric energy demand together with the house ones. PV/T connection to the national grid is considered to account for the electricity excess/deficit with respect to the HP and house loads. The SAHP system considered in this work is designed to cover both Domestic Heat Water (DHW) and Space Heating (SH) consumptions of a single-family house. The heat pump nominal heating capacity and COP are equal to $8.52 \mathrm{~kW}$ and 3.19 respectively, whereas PV/T module performance feature commercially available ones (SoLink, 2017). The HP is modelled in MATLAB ${ }^{\circledR}$ considering the governing equations of each component as detailed in the next section, whereas the $\mathrm{PV} / \mathrm{T}$ are modelled combining datasheet information and experimental measurements carried out at SolarTech ${ }^{\mathrm{Lab}}$ of Politecnico di Milano (Bombarda, et al., 2016).

\section{Mathematical Model}

The SAHP model solves heat and mass balances assuming stationary conditions, neglecting the transient effect of solar radiation $(\mathrm{G})$ variation and the thermal energy storage balance heat load variations. All the components of the HP (compressor, condenser, evaporator and expansion valve) and PV/T modules are considered as blackboxes, with governing equations to describe their physical behavior. The aim is to have a complete model that correctly describes the considered system within limited computational time to perform a detailed analysis in different ambient conditions and with a different number as well as typology of PV/T modules. Fig. 2 shows the refrigerant loop, the domestic water loop (as called primary circuit) and the water-glycol loop (as called secondary circuit). Glycol is used to prevent water freezing in winter time. HP operating points are numbered starting from the inlet of the compressor following the refrigerant fluid. 


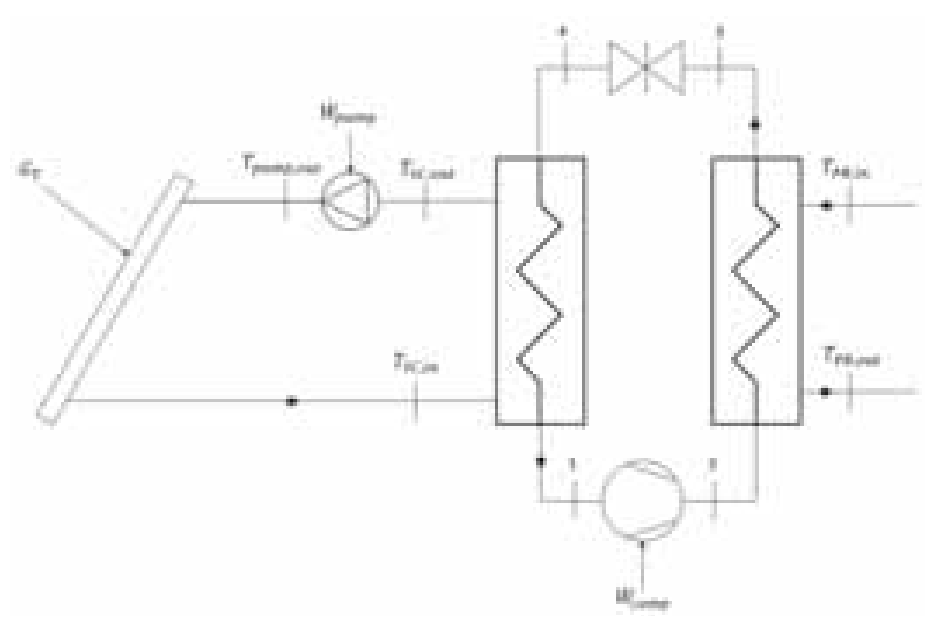

Fig. 2: Schematic of mathematical model

\subsection{Compressor}

The behavior of the compressor is described with polynomial equations to determine the refrigerant flow rate $\dot{m}_{\text {refr }}$ and the electric power consumption $\dot{W}_{c o m p}$ as functions of condensation and evaporation temperatures $T_{\text {cond }}$ and $T_{\text {evap }}$. The 10 coefficients of the polynomial equations are provided by manufacturers (eq. 1 and eq. 2 ).

$$
\begin{aligned}
& \dot{m}_{\text {refr }}=a_{0}+a_{1} T_{E}+a_{2} T_{C}+a_{3} T_{E}^{2}+a_{4} T_{E} T_{C}+a_{5} T_{C}^{2}+a_{6} T_{E}^{3}+a_{7} T_{E}^{2} T_{C}+a_{8} T_{E} T_{C}^{2}+a_{9} T_{C}^{3} \\
& \dot{W}_{c o m p}=b_{0}+b_{1} T_{E}+b_{2} T_{C}+b_{3} T_{E}^{2}+b_{4} T_{E} T_{C}+b_{5} T_{C}^{2}+b_{6} T_{E}^{3}+b_{7} T_{E}^{2} T_{C}+b_{8} T_{E} T_{C}^{2}+b_{9} T_{C}^{3}
\end{aligned}
$$

Coefficients $a_{i}$ and $b_{i}$ are evaluated by manufacturers at defined conditions. The compressor used in this work (Emerson ZH30K4E-TFD) (Emerson, 2017) has superheating temperature set to 5K, eq. 3 and eq. 4 determine the refrigerant flow rate and the electric power consumption with a different superheating:

$\left.\dot{m}_{\text {refr }}\right|_{\Delta T_{s h}}=\left.\dot{m}_{\text {refr }}\right|_{\Delta T_{\text {sh }}=5 K} \cdot \frac{\rho\left(p_{\left.\text {evap }, T_{\text {evap }}+\Delta T_{s h}\right)}\right.}{\rho\left(p_{\text {evap }}, T_{\text {evap }}+5 K\right)}$
$\left.\dot{W}_{\text {comp }}\right|_{\Delta T_{s h}}=\left.\dot{W}_{\text {comp }}\right|_{\Delta T_{\text {sh }}=5 K} \cdot \frac{\rho\left(p_{\text {evap }}, T_{\text {evap }}+\Delta T_{s h}\right)}{\rho\left(p_{\text {evap }, T_{\text {evap }}+5 K}\right)}$

However, part of the electric power absorbed by the compressor is dissipated as heat to the environment. This heat is assumed to be $10 \%$ of the total power, and this assumption is taken into account by means of eq. 5 :

$h_{2}=h_{1}+0.9 \cdot \frac{\dot{W}_{c o m p}}{\dot{m}_{r e f r}}$

The refrigerant at point 2 is superheated vapor and enters the condenser. The set of the compressor operating conditions is defined by the envelope, as shown in Fig. 3.

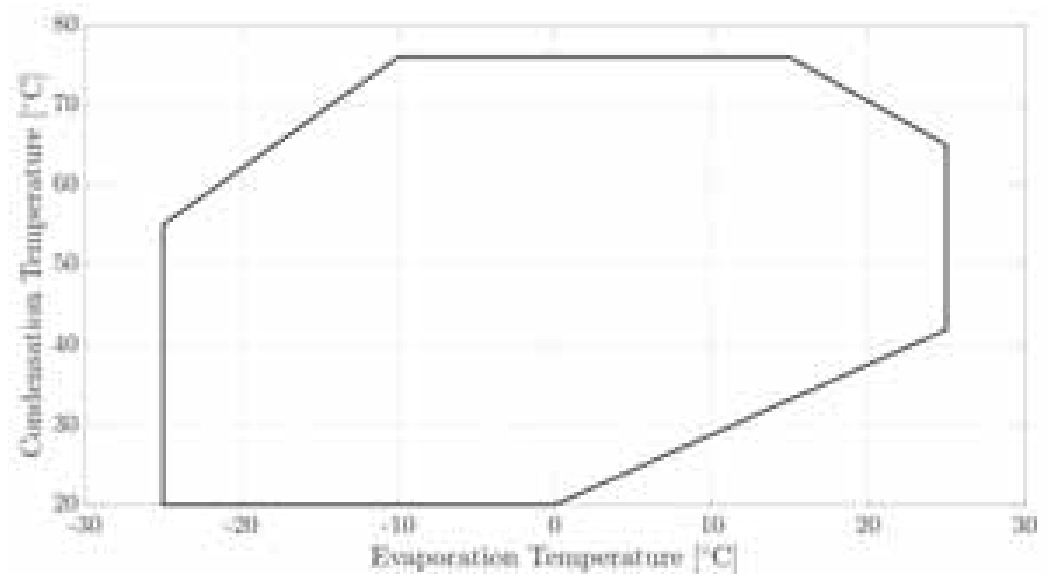

Fig. 3: Operating field of the compressor 


\subsection{Condenser}

The condenser is a plate heat exchanger that transfers heat from the working fluid of the heat pump to the domestic water. This component is modelled by means of the eq. 6 :

$\dot{Q}_{\text {condenser }}=\sum_{i=0}^{\text {zones }} U_{i} \cdot A_{i} \cdot L M T D_{i}$

Where $L M T D_{i}$ is the logarithmic mean temperature difference of each zone. The condenser is divided into two parts: the de-superheating zone and the condensation zone. Subcooling zone is neglected because of its negligible impact on the condenser's energy balance. For the two modelled sections, thermal transmittance (U) is calculated as the sum of the heat transfer contributions related to the refrigerant fluid, the domestic water and the thickness of the plate between them, as shown in eq. 7 .

$U=\left(\frac{1}{h_{\text {conv,refr }}}+\frac{s_{P L A T E}}{k_{P L A T E}}+\frac{1}{h_{\text {conv,water }}}\right)^{-1}$

The conductive heat transfer coefficient $h_{\text {conv }}$ is determined using the correlation of $\operatorname{Kim}(\mathrm{Kim}, 1999)$ for singlephase fluids (superheated refrigerant vapor and liquid water) and the modified correlation of Shah (Shah, 1979) for the two-phase refrigerant fluid, as shown in eq. 8 and eq. 9 respectively:

$N u=0.295 \cdot R e^{0.64} \cdot \operatorname{Pr}^{0.32} \cdot(\pi / 2-\beta)^{0.09}$

$h_{\text {conv }}=\int_{0}^{1} 0.2092 \cdot R e_{L S}^{0.78} \cdot P r_{L S}^{0.33} \cdot \frac{k_{L S}}{D_{H}} \cdot\left[(1-x)^{0.8}+\frac{3.8 \cdot x^{0.76} \cdot(1-x)^{0.04}}{\left(\frac{p_{S A T}}{p_{C R I T}}\right)^{0.38}}\right] d x$

where $N u=\frac{h_{\text {conv }} \cdot D_{H}}{k}$ is the Nusselt number, $\operatorname{Re}=\frac{G \cdot D_{H}}{\mu}$ is the Reynolds number, $\operatorname{Pr}=\frac{\mu \cdot C_{p}}{k}$ is the Prandtl number, $G=\frac{\dot{m}_{r e f r}}{N \cdot B \cdot t}$ is the specific flow rate of a single channel, $D_{H}=2 \cdot t$ is the hydraulic diameter, $\beta=65^{\circ} \cdot \frac{\pi}{180^{\circ}}$ is the Chevron angle and $N=\frac{N_{\text {condenser }}-1}{2}$ is the number of channels for the refrigerant flow. B and t are set as $0.08 \mathrm{~m}$ and $0.00205 \mathrm{~m}$. Thermophysical properties are evaluated at mean temperature of the zone for the mono-phase fluids. The two areas of the heat transfer result from the model solution while the overall condenser surface defined at design condition, will be assumed constant in any other operating point, as discussed in next section.

With the aim of enhancing model accuracy, pressure drops are considered. Longo correlation (Longo \& Zilio, 2013 ) is used to represent the physic behavior of the condensation, as shown in eq. 10.

$\Delta p=\frac{15}{8} \cdot K E V \quad$ with $K E V=\frac{G^{2}}{2 \cdot \bar{\rho}}$

For the de-superheating part, Martin correlation (Martin, 1996) is implemented in eq. 11 and eq. 12.

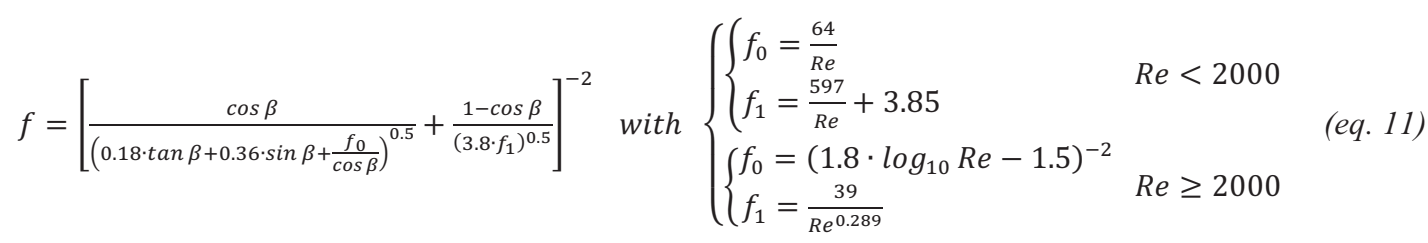

$\Delta p=f \cdot \frac{L}{D_{H}} \cdot K E V$

\subsection{Expansion Valve}

The working principle of the expansion valve is described by an isenthalpic transformation, where the refrigerant undergoes a pressure drop with no enthalpy variation. Eq. 13 expresses this behavior:

$h_{4}=h_{3}$

The task of this component is to maintain a defined superheating of refrigerant vapor at the evaporator outlet to avoid liquid droplets transport inside the compressor. In this paper, a constant superheating of $5 \mathrm{~K}$ is used.

\subsection{Evaporator}


This component, similarly to the condenser, is a plate heat exchanger, so it is modelled in a similar way. Evaporation and superheating zones are identified. Tough the superheating section is small in terms of heat transfer rate, it has to be included in order to have an accurate model. The governing equation is:

$\dot{Q}_{\text {evaporator }}=\sum_{i=0}^{\text {zones }} U_{i} \cdot A_{i} \cdot L M T D_{i}$

Thermal transmittance $\mathrm{U}$ is calculated using eq. 7 and the convective heat transfer coefficient $h_{\text {conv }}$ is obtained from eq. 8 for single-phase fluids and from Han, Lee and Kim correlation (Han, et al., 2003) for the evaporating refrigerant fluid, as shown in eq. 15.

$N u=G e_{1} \cdot R e_{L S}^{G e_{2}} \cdot B o_{e q}^{0.3} \cdot P r_{L S}^{0.4}$

$G e_{1}$ and $G e_{2}$ are functions of the heat exchanger geometry and $B o_{e q}$ is the boiling number. They can be evaluated as follow:

$G e_{1}=2.81 \cdot\left(\frac{P_{C O R}}{D_{H}}\right)^{-0.041} \cdot(\pi / 2-\beta)^{-2.83}$

$G e_{2}=0.746 \cdot\left(\frac{P_{C O R}}{D_{H}}\right)^{-0.082} \cdot(\pi / 2-\beta)^{0.61}$

$B o_{e q}=\frac{q_{w a l l}}{G_{e q} \cdot \Delta h_{L-V}}$

where $P_{C O R}$ is the corrugation pitch, $q_{\text {wall }}=G \cdot\left(h_{V S}-h_{4}\right)$ is the specific thermal power at the wall and $G_{e q}=$ $G \cdot\left[1-x_{4}+x_{4} \cdot\left(\frac{\rho_{L S}}{\rho_{V S}}\right)^{0.5}\right]$ is the equivalent specific flow rate of a single channel and $x_{4}$ is the fraction of vapor in the refrigerant flow rate at the inlet of the evaporator. In analogy with the condenser, also the evaporation and superheating areas are obtained by solving the analytical model and the total surface of the evaporator is determined at design condition.

To model pressure drop, as condenser the correlation of Martin is used for the superheated vapor. In the evaporation zone, the following correlation is chosen (Longo, et al., 2016).

$\Delta p=\frac{5}{3} \cdot K E V$

(eq. 19)

\subsection{Refrigerant Fluid}

The fluid used in the heat pump is R134a and is modelled using lookup tables created starting from the software REFPROP 9.1 (NIST, 2017), which implements equations of state of different compounds. The selected discretization step $\left(1{ }^{\circ} \mathrm{C}\right.$ for the temperature, $25 \mathrm{kPa}$ for the pressure and $500 \mathrm{~J} / \mathrm{kg}$ for the enthalpy) of the tables was selected to guarantee high accuracy while keeping a fast model convergence.

\subsection{PV/T Modules}

For solar panels, both thermal and electric modeling is needed. Thermal behavior is described by eq. 20, which takes into account optical losses of the glass and of the PV array and convective losses to the environment. Here, radiative losses are linearized with first order temperature differences which is a reasonable assumption considering the low operating temperature.

$\eta_{t h}=\eta_{\text {opt }}-a_{1} \cdot \frac{\left(T_{\text {pump }, o u t}+T_{S C, \text { in }}\right) / 2-T_{a m b}}{G_{T}}=\frac{\dot{V}_{S C} \cdot \rho_{S C} \cdot C_{S C} \cdot\left(T_{\text {pump }, \text { out }}-T_{S C, \text { in }}\right)}{G_{T} \cdot A_{\text {panel }} N_{\text {panels }}}$

Coefficients $\eta_{\text {opt }}$ and $a_{1}$ are obtained from an experimental campaign carried out at SolarTech ${ }^{\mathrm{Lab}}$ at Politecnico di Milano between spring and summer of 2017. PV/T modules are roll-bond type, with poly-crystalline solar cells. Tab. 1 summarized the main characteristics of panels used.

Tab. 1: Characteristic of PV/T panels

\begin{tabular}{ccccccc}
\hline $\boldsymbol{A}_{\text {panel }}\left[\mathrm{m}^{2}\right]$ & $\boldsymbol{\eta}_{\text {opt }}$ & $\boldsymbol{a}_{\mathbf{1}}\left[\left(\mathrm{W} / \mathrm{m}^{2}\right) / \mathrm{K}\right]$ & $\boldsymbol{\eta}_{\text {el,REF }}$ & $\dot{\boldsymbol{W}}_{\boldsymbol{R E F}}\left[\mathrm{W}_{\mathrm{p}}\right]$ & $\boldsymbol{\gamma}[\% / \mathrm{K}]$ & $\boldsymbol{T}_{\text {cell,REF }}\left[{ }^{\circ} \mathrm{C}\right]$ \\
\hline 1.63 & 0.528 & 13.658 & 0.153 & 250 & 0.42 & 56 \\
\hline
\end{tabular}


Electric behavior of PV cells is modelled using the power coefficient approach. The generated power is function of the solar irradiance $\mathrm{G}$ and the temperature of the cells (both considered uniform on the panel surface), as shown in eq. 21 .

$\eta_{e l}=\eta_{e l, R E F} \cdot\left[1+\gamma \cdot\left(T_{\text {cell }}-T_{\text {cell,REF }}\right)\right]=\frac{\dot{W}_{e l}}{G_{T} \cdot A_{\text {panel }} N_{\text {panels }}}$

where $\eta_{e l, R E F}$ and $T_{c e l l, R E F}$ are taken from the datasheet of the panel and $T_{c e l l}$ is evaluated as the mean fluid temperature of the fluid circulating on the panel $\bar{T}_{\text {fluid }}$ plus a constant value, which is here assumed equal to $10 \mathrm{~K}$.

Pressure drops of PV/T panels are modelled using a polynomial curve of grade two extrapolated from a test done by the manufacturer, as shown in eq. 22 .

$\Delta p_{\text {panel }}=980.9 \cdot \dot{V}_{S C}^{2}+4475 \cdot \dot{V}_{S C}$

(eq. 22)

where the volumetric flow rate is expressed in $[1 / \mathrm{min}]$.

\subsection{Hydraulic Loop}

Secondary hydraulic loop is considered in the model including a volumetric pump, whose power consumption is modelled as follow:

$\dot{W}_{\text {pump }}=\dot{V}_{S C} \cdot \frac{\Delta p_{S C}}{\eta_{\text {pump }}}$

Pump efficiency is assumed to be constant equal to $15 \%$, a typical value for centrifugal pumps, and the pressure drop is calculated considering the hydraulic circuit, the evaporator and PV/T modules. Tab. 2 summarizes the characteristic of the hydraulic circuit, while eq. 24 shows the modelization of exchanger pressure drops.

Tab. 2: Characteristic of secondary hydraulic circuit

\begin{tabular}{ccc}
\hline Tubes Length $[\mathrm{m}]$ & Losses $\left[\mathrm{Pa} / \mathrm{m}^{*}(1 / \mathrm{min})^{2}\right]$ & Volumetric Glycol Fraction $\left(X_{S C}\right)$ \\
\hline 7 & 9 & 0.3 \\
\hline
\end{tabular}

$\Delta p_{\text {evaporator }}=51570 \cdot \dot{V}_{S C}^{2}+3.229 \cdot \dot{V}_{S C}-0.2362$

(eq. 24)

where the volumetric flow rate is expressed in [1/min]. However, a fraction of the pump power is dissipated as heat, which produces an increase of temperature of the fluid. This increase is considered by means of the eq. 25 .

$\dot{Q}_{\text {diss }, \text { pump }}=\dot{V}_{S C} \cdot \Delta p_{S C} \cdot \frac{1-\eta_{\text {pump }}}{\eta_{\text {pump }}}=\dot{V}_{S C} \cdot \rho_{S C} \cdot c_{S C} \cdot\left(T_{\text {pump.out }}-T_{S C, \text { out }}\right)$

\section{Model Resolution and Optimization}

Equations described in Section 3 are implemented in a MATLAB ${ }^{\circledR}$ code. To resolve the SAHP system, other equations are needed and a design condition must be defined. Firstly, energy balances of each zone of condenser and evaporator and surface balances of heat exchangers are introduced, as shown in the following equations.

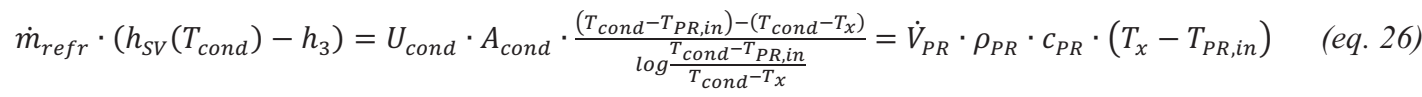

$$
\begin{aligned}
& \dot{m}_{\text {refr }} \cdot\left(h_{2}-h_{S V}\left(T_{\text {cond }}\right)\right)=U_{d e-s h} \cdot A_{d e-s h} \cdot \frac{\left(T_{\text {cond }}-T_{x}\right)-\left(T_{2}-T_{P R, o u t}\right)}{\log _{\frac{T_{c o n d}-T_{x}}{T_{2}-T_{P R, \text { out }}}}}=\dot{V}_{P R} \cdot \rho_{P R} \cdot c_{P R} \cdot\left(T_{P R, \text { out }}-T_{x}\right) \quad \text { (eq. 27) } \\
& \dot{m}_{\text {refr }} \cdot\left(h_{S V}\left(T_{\text {evap }}\right)-h_{4}\right)=U_{\text {evap }} \cdot A_{\text {evap }} \cdot \frac{\left(T_{S C, \text { out }}-T_{\text {evap }}\right)-\left(T_{y}-T_{\text {evap }}\right)}{\log \frac{T_{S C, \text { out }}-T_{\text {evap }}}{T_{y}-T_{\text {evap }}}}=\dot{V}_{S C} \cdot \rho_{S C} \cdot c_{S C} \cdot\left(T_{S C, \text { out }}-T_{y}\right) \quad \text { (eq. 28) } \\
& \dot{m}_{\text {refr }} \cdot\left(h_{1}-h_{S V}\left(T_{\text {evap }}\right)\right)=U_{s h} \cdot A_{s h} \cdot \frac{\left(T_{y}-T_{\text {evap }}\right)-\left(T_{S C, i n}-T_{1}\right)}{\log \frac{T_{y}-T_{\text {evap }}}{T_{S C, i^{-}-T_{1}}}}=\dot{V}_{S C} \cdot \rho_{S C} \cdot c_{S C} \cdot\left(T_{y}-T_{S C, \text { in }}\right) \quad \text { (eq. 29) } \\
& A_{\text {condenser }}=A_{\text {cond }}+A_{\text {de-sh }} \\
& A_{\text {evaporator }}=A_{\text {evap }}+A_{\text {sh }}
\end{aligned}
$$


$T_{x}$ and $T_{y}$ are the temperatures of the primary and secondary circuits at which the condensation and evaporation of the refrigerant fluid starts and stops respectively. The design condition determines the total area of the condenser and the evaporator together with the correct number of plates of the two heat exchangers which are determined with an empirical correlation (eq. 32):

$N_{\text {plates }}=2 \cdot\left\lceil\frac{\left(\frac{\dot{Q}_{H X}}{\dot{Q}_{\text {plate }}}+2\right)}{2}\right\rceil$

$\dot{Q}_{\text {plate }}$ is the heat exchanged by a single plate, set at $200 \mathrm{~W} /$ plate, after a preliminary analysis on different commercial softwares. Finally, $A_{\text {condenser }}, A_{\text {evaporator }}$, and the two $\dot{Q}_{H X}$ are obtained solving the complete model in a standard working condition that is common used to build the datasheet of a water-to-water heat pump. Tab. 3 shows the temperatures of this condition.

Tab. 3: Temperatures at the design condition

\begin{tabular}{cccccccc}
\hline $\boldsymbol{T}_{\text {evap }}\left[{ }^{\circ} \mathrm{C}\right]$ & $\Delta \boldsymbol{T}_{\text {sh }}[\mathrm{K}]$ & $\boldsymbol{T}_{\boldsymbol{S C , \text { in }}}\left[{ }^{\circ} \mathrm{C}\right]$ & $\boldsymbol{T}_{\boldsymbol{S C , o u t}}\left[{ }^{\circ} \mathrm{C}\right]$ & $\boldsymbol{T}_{\text {cond }}\left[{ }^{\circ} \mathrm{C}\right]$ & $\Delta \boldsymbol{T}_{\text {sub }}[\mathrm{K}]$ & $\boldsymbol{T}_{P R, \text { in }}\left[{ }^{\circ} \mathrm{C}\right]$ & $\boldsymbol{T}_{\boldsymbol{P R}, \text { out }}\left[{ }^{\circ} \mathrm{C}\right]$ \\
\hline 2 & 5 & 10 & 7 & 50 & 0 & 40 & 45
\end{tabular}

The model developed is a system of non-linear equations, that can be solved with the function fsolve available in the MATLAB ${ }^{\circledR}$ library. Fig. 4 describes the logical steps followed for all the simulations:

- In the first step, geometrical parameters of the evaporator and the condenser are calculated from the design condition. In this situation, $T_{\text {evap }}$ and $T_{\text {cond }}$ are set, as well as temperatures at the inlet and at the outlet of the heat exchangers and superheating in point 1 and subcooling in point 3 of the refrigerant cycle. All the unknown variables can be explicated and the solver is not required. Solar irradiance and ambient temperature for a fixed number of PV/T modules are a result in this case and their values can be used to do a preliminary evaluation of the energetic feasibility of the system;

- Secondly, fsolve function solves the system of equations (that with some passages can be reduced to a system of 5 non-linear equations in 5 variables, which are $T_{\text {evap }}, T_{\text {cond }}, T_{S C \text {,out }}, A_{\text {evap }}$ and $A_{\text {cond }}$ ), using as input parameters the solar irradiance and the ambient temperature, which are exogenous variables, and the number of $\mathrm{PV} / \mathrm{T}$ panels;

- If a solution is found by the solver, a series of physical boundaries are introduced to check the working point feasibility. The following equations explain this approach.

$$
\begin{aligned}
& \operatorname{img}(\text { solution }) \neq 0 \quad \forall \text { solution } \\
& A_{\text {evap }}, A_{\text {cond }}>0 \\
& \text { envelope }\left(T_{\text {evap }}, T_{\text {cond }}\right)=\text { true } \\
& T_{S C, \text { out }}>T_{\text {freezing }}\left(X_{S C}\right)
\end{aligned}
$$

Constrains are applied after the resolution of the system to avoid solver function failure when an intermediate unfeasible solution is found but the final solution is feasible.

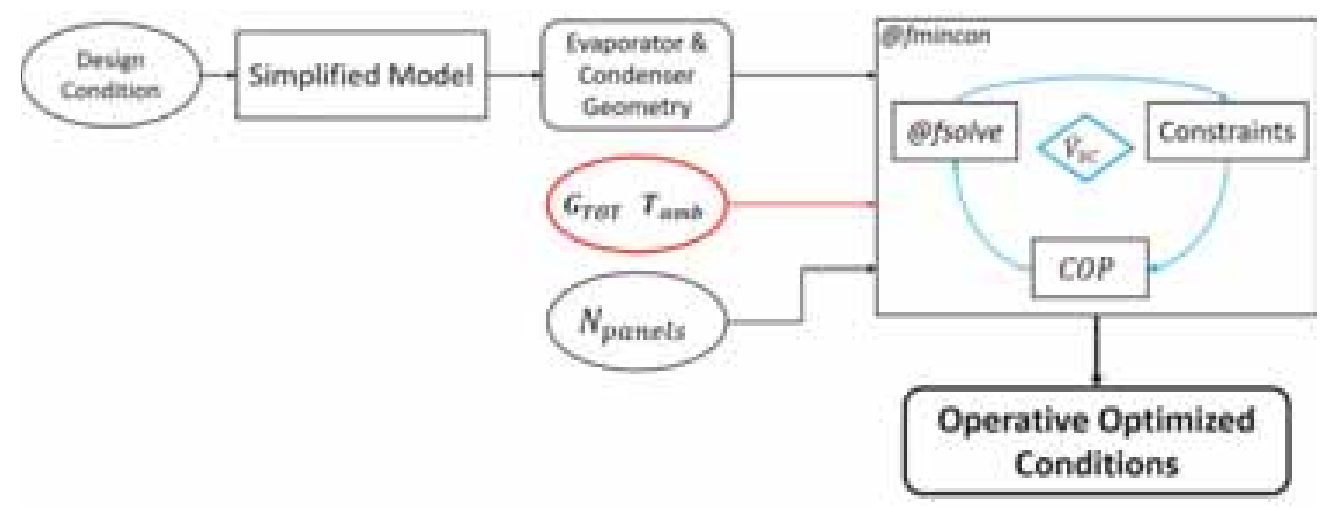

Fig. 4: Explanation of the logical steps followed for a simulation 
In addition to the physical model of the SAHP, an optimization tool is used to maximize the performance parameter COP (Coefficient of Performance), which is expressed by eq. 37.

COP $=\frac{\dot{Q}_{\text {cond }}}{\dot{W}_{\text {comp }}+\dot{W}_{\text {pump }}}$

The optimization is done with the function fmincon varying the volumetric flow rate $\dot{V}_{S C}$. Another constraint is introduced to implement the behavior of the PV/T panels: the flow rate must be between $0.008 \overline{3} \mathrm{l} / \mathrm{s}(0.5 \mathrm{l} / \mathrm{min})$ and $0.0 \overline{3} \mathrm{l} / \mathrm{s}(2 \mathrm{l} / \mathrm{min})$ for each line of PV/T panels in parallel to avoid low heat transfer coefficient and too high pressure drops. Fig. 5 is an example that shows the presence of a maximum of the COP in the range previously defined: thermal power at the condenser presents a limited grown, following the grown of the secondary loop flow rate, the electric consumption of the compressor is approximatively constant but the pump consumption increases strongly with a quadratic behavior. The opposite trends result in a maximum of the COP.

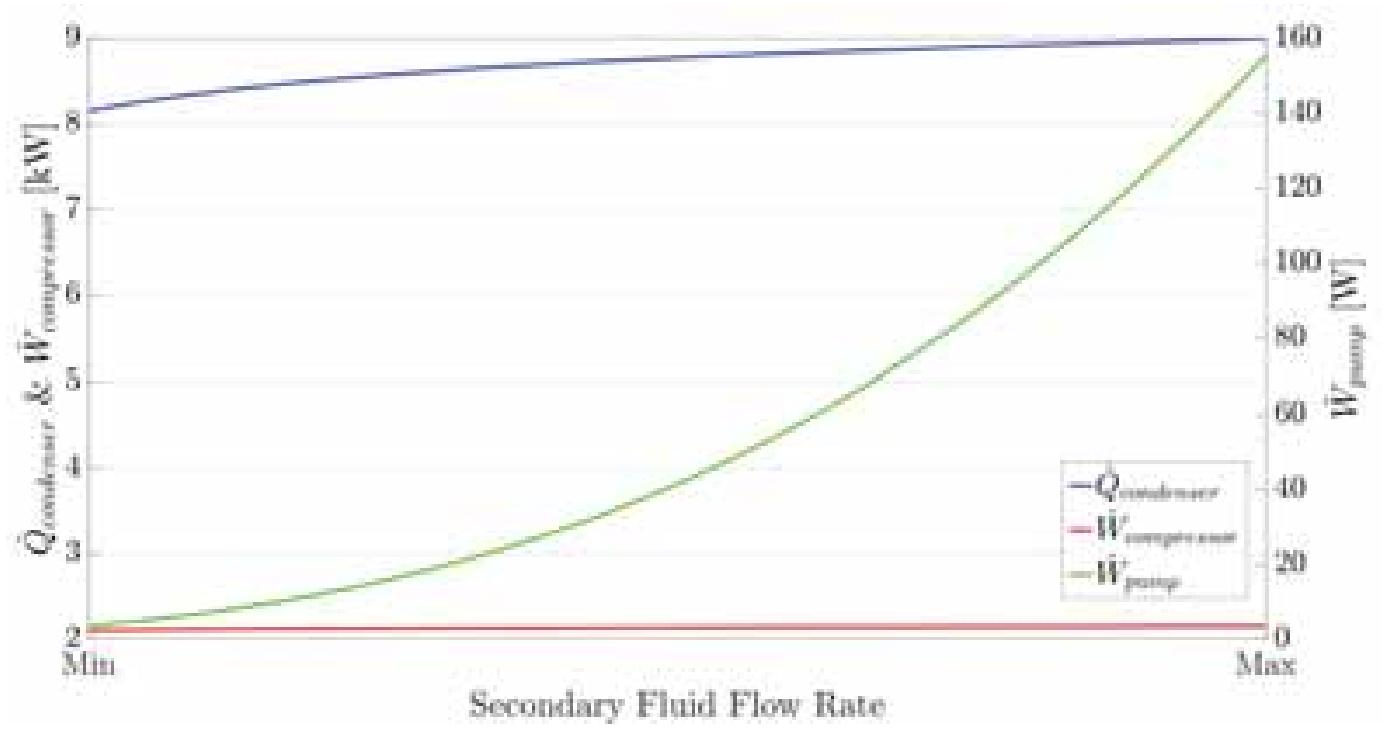

Fig. 5: Explanation of the presence of a maximum of COP as function of secondary fluid flow rate

In the end, Tab. 4 shows the results of the mathematical model obtained in the design condition, which are the same independently of the number of PV/T modules. Tab. 5 shows the solar irradiance needed to produce heat required in the evaporator in the design condition for 12,16, 20 and $24 \mathrm{PV} / \mathrm{T}$ panels respectively.

Tab. 4: Results of the model in the design condition

\begin{tabular}{|c|c|c|c|c|c|c|}
\hline COP & $\begin{array}{c}\dot{Q}_{\text {condenser }} \\
{[\mathbf{k W}]}\end{array}$ & $\begin{array}{c}A_{P L A T E, \text { condenser }} \\
{\left[\mathrm{m}^{2}\right]}\end{array}$ & $\begin{array}{c}A_{P L A T E, \text { evaporator }} \\
{\left[\mathrm{m}^{2}\right]}\end{array}$ & $N_{P L A T E, \text { condenser }}$ & $N_{P L A T E, \text { evaporator }}$ & $\begin{array}{c}T_{a m b} \\
{\left[{ }^{\circ} \mathrm{C}\right]}\end{array}$ \\
\hline 3.19 & 8.52 & 0.0258 & 0.0197 & 46 & 36 & 7 \\
\hline
\end{tabular}

Tab. 5: Solar irradiance required in the design condition with different number of PV/T modules

\begin{tabular}{ccccc} 
& $12 P V / T$ & $16 P V / T$ & $20 P V / T$ & $24 P V / T$ \\
\hline$G_{T}\left[\mathrm{~W} / \mathrm{m}^{2}\right]$ & 642.95 & 494.34 & 404.55 & 344.47 \\
\hline
\end{tabular}




\section{Results}

Starting from the design conditions, the model is used to assess the performance of a SAHP system at different ambient conditions. In particular, solar irradiance was varied between $0 \mathrm{~W} / \mathrm{m}^{2}$ to $1000 \mathrm{~W} / \mathrm{m}^{2}$ with steps of 100 $\mathrm{W} / \mathrm{m}^{2}$, ambient temperature from $-20^{\circ} \mathrm{C}$ to $20^{\circ} \mathrm{C}$ with steps of $5^{\circ} \mathrm{C}$.

Fig. 6 shows the behavior of the COP as a function of solar irradiance and ambient temperature for a layout with 12 and 24 panels, corresponding to a peak power of the installation of $3 \mathrm{~kW}_{\mathrm{el}}$ and $6 \mathrm{~kW}_{\mathrm{el}}$ respectively. As expected, COP increases with the ambient temperature and solar irradiance. The dependency is linear and the influence of solar irradiance is more pronounced than the one the ambient temperature. The case with more PV/T modules has better performance, even though differences are quite limited. In both cases, a non-operating zone is present (blue zone) representing the freezing conditions of the water plus glycol mixture points.

It is important to notice that the system can work also during the night with an acceptable COP (greater than 2). This is possible because of the high $\mathrm{a}_{1}$ of the $\mathrm{PV} / \mathrm{T}$ panels that permits to absorb enough energy from the environment (evaporation temperature is lower than the ambient one in these cases) and provide the heat required by the heat pump. This possibility increases the flexibility of the system extending the achievable working conditions to the all day.
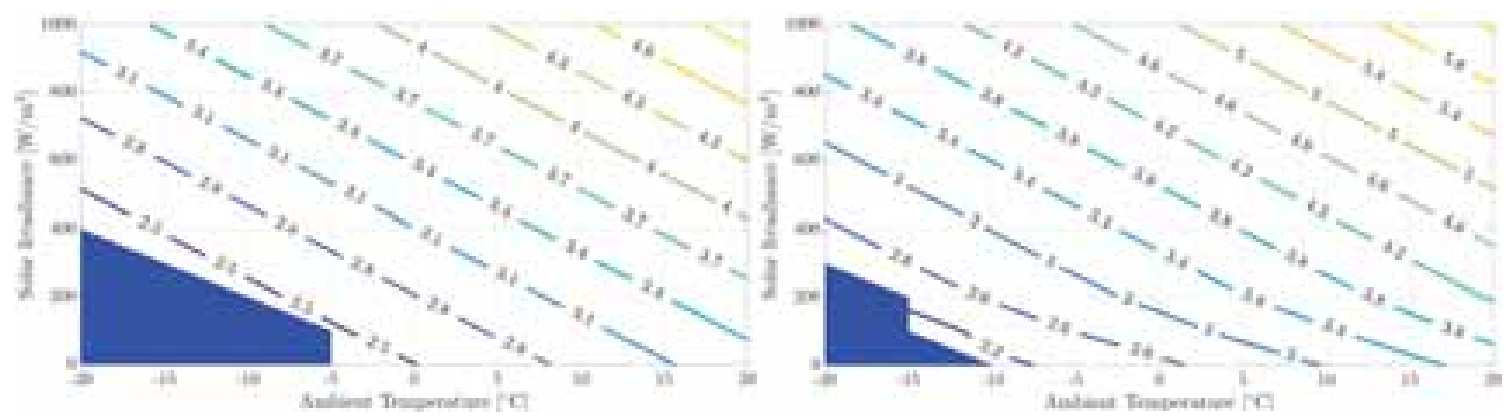

Fig. 6: Representation of COP for an indirect SAHP with 12 (left) and 24 (right) PV/T panels as a function of ambient temperature and solar irradiance

In Fig. 7, the ratio between the electric power produced by the PV/T modules and the power consumption of the $\mathrm{HP}$ and circulating pump for 12 (left) and 24 (right) PV/T is reported. When the ratio is greater than 1, the system is energetic self-sufficient, reducing the impact of heat pump consumption on the energetic costs and also the impact of the renewable power production on the national grid: the simultaneous production and consumption by the HP reduces the electricity import/export with respect to a more conventional solution with only PV modules and conventional heating system. In the case with $12 \mathrm{PV} / \mathrm{T}$ panels, the energetic self-sufficient condition is reached only with a high solar irradiance (between 600 and $800 \mathrm{~W} / \mathrm{m}^{2}$ ), instead of the case with 24 panels that a lower value is needed, around $200-300 \mathrm{~W} / \mathrm{m}^{2}$.
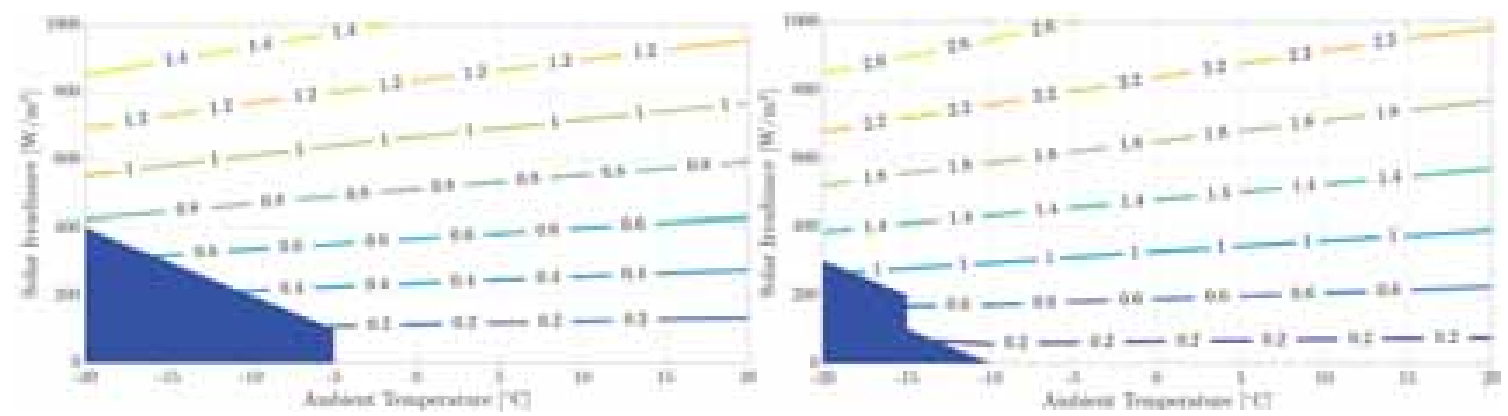

Fig. 7: Representation of the ratio between the electric power produced by PV/T modules and electric consumption of the SAHP with 12 (left) and 24 (right) PV/T panels as a function of ambient temperature and solar irradiance

Fig. 8 presents the advantages of this system with 12 PV/T panels respect of traditional technologies (air heat pump and PV modules). In the left graph, the difference between the inlet temperature of the evaporator and the ambient temperature is shown. It is possible to see that in most cases the temperature of the SAHP heat source is higher than the air temperature, which is the source of the standard air-to-water technology. Therefore, the proposed system improves the HP COP at constant thermal power produced, reducing the operational costs of the 
machine. In addition, the typical performance decay of air-to-water heat pumps at ambient temperature below zero as consequence of the frost formation is not present here further increasing the SAHP performance gain.

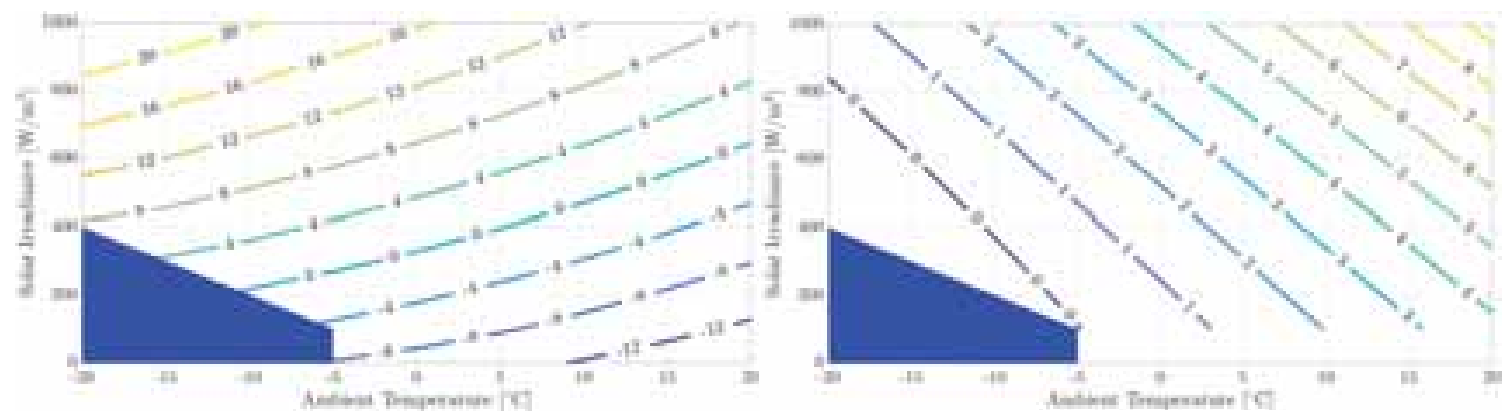

Fig. 8: Representation of the difference between the secondary fluid inlet temperature and the ambient temperature (left) and the increase of electric production of the PV/T modules (right) as functions of ambient temperature and solar irradiance

On the right of Fig. 8 the advantages in terms of electric power production are also reported, outlining the benefits of cooled cells with respect to conventional modules. As it is described in eq. 21, decreasing the temperature of the cell enhances the electric power production at the same solar irradiance. This effect is mainly visible with favorable ambient conditions and the increase reaches 8-9\%. The standard PV module used for the comparison has the same peak power of the PV/T module and the power production is evaluated from the NOCT method.

\section{Conclusions}

In this paper, an analytical model of a solar-assisted heat pump combined with Photovoltaic Thermal modules is developed using the software MATLAB ${ }^{\circledR}$. Governing equations for the heat pump and characteristic curve of the $\mathrm{PV} / \mathrm{T}$ modules are identified. The compressor is modelled with polynomial expressions provided by manufacturer as function of the condensation and evaporation temperatures. Condenser and evaporator are discretized in two zones each (de-superheating and condensation the former, evaporation and superheating the latter) and physical behaviors are described by mean of the thermal transmittance U, evaluated using correlations from literature for mono-phase and two-phase heat transfer. The modeling considers also an isenthalpic expansion valve and R134a refrigerant fluid is used. Regarding PV/T modules, thermal and electric power are determined using the characteristic curve and the power method typical of PV technology. Two hydraulic circuits are considered to transfer the heat from the PV/T panels to the evaporator and from the condenser to the thermal load. A mixture of water and glycol is considered in the PV/T loop to prevent freezing phenomena.

MATLAB $^{\circledR}$ fsolve function is used to resolve the system of equations related to the SAHP. The sizing of the heat exchangers is performed at design condition that is the same of a standard water-to-water heat pump. An optimization tool is also used to find the optimum operating condition of the whole system accounting for the circulating flow in the PV/T modules. This tool is the fmincon function of MATLAB ${ }^{\circledR}$ library. Solar irradiance and ambient temperature are varied to obtain the performance map of the system assuming different number of $\mathrm{PV} / \mathrm{T}$ panels.

Results show that the COP of the SAHP varies between 2.5 and 4.9 in the case with $12 \mathrm{PV} / \mathrm{T}$ panels, and between 2.2 and 6.2 with $24 \mathrm{PV} / \mathrm{T}$ modules. The advantage of having more PV/T modules is quite limited in terms of thermal performance, but enlarges the operating conditions of the system (i.e. minimum ambient temperature) and increases the electric production. The study shows that the heat recovered by the PV/T modules is enough to permit the functioning of the heat pump also during the night with an acceptable COP (greater than 2), increasing the flexibility of the system. Other advantages are found regarding the temperature of the cold source respect of an air-to-water heat pump and the electric power production compared to a standard PV panel. For the first case, a higher temperature than the ambient temperature at the inlet of the evaporator is reached in most of the considered conditions. Advantages are even higher when the ambient temperature goes below zero, where a standard air source heat pump suffers of frost formation. Related to the electric production, the present paper shows that a cooled PV/T panel produces more power respect of a non-cooled PV panel, reaching values of $8-9 \%$ over referred to the standard production.

Future works will investigate all the advantages pointed out in this paper with experimental campaigns to confirm the results of the model. 


\section{References}

Aste, N., Del Pero, C. \& Leonforte, F., 2014. Water flat plate PV-thermal collectors. A review. Solar Energy, Volume 102, pp. 98-115, DOI: https://doi.org/10.1016/j.solener.2014.01.025.

Bombarda, P. et al., 2016. Thermal and electric performances of roll-bond flat plate applied to conventional PV modules for heat recovery. Applied Thermal Energy, Volume 105, pp. 304-313, DOI: https://doi.org/10.1016/j.applthermaleng.2016.05.172.

Calise, F., Dentice d'Accadia, M., Figaj, R. \& Vanoli, L., 2016. A novel solar-assisted heat pump driven by photovoltaic/thermal collectors: Dynamic simulation and thermoeconomic optimization. Energy, Volume 95, pp. 346-366, DOI: https://doi.org/10.1016/j.energy.2015.11.071.

Emerson, 2017. Emerson. [Online] Available at: http://www.emersonclimate.com/europe/eneu/products/compressors/scroll compressors/comfort/heating/copeland scroll heating compressors/pages/cope $\underline{\text { land scroll heating technical details.aspx? what }=1 \text { ist\&prodid }=30867 \& b r a=1 \& \text { fam }=17 \& p r o d=c \& A r=H P \& p r o d}$ pic $=1 \&$ ref $=8 \& p$ [Accessed 1 October 2017].

Han, D., Lee, K. \& Kim, Y., 2003. Experiments on the characteristics of evaporation of R410A in brazed plate heat exchangers with different geometric configurations. Applied Thermal Engineering, 23(10), pp. 1209-1225, DOI: https://doi.org/10.1016/S1359-4311(03)00061-9.

Ji, J. et al., 2008. Experimental study of photovoltaic solar assisted heat pump system. Solar Energy, Volume 82, pp. 43-52, DOI: https://doi.org/10.1016/j.solener.2007.04.006.

Kim, Y., 1999. An Experimental Study on Evaporation Heat Transfer Characteristics and Pressure Drop in Plate Heat Exchanger. M.S. thesis, Yonsei University.

Kumar, A., Baredar, P. \& Qureshi, U., 2015. Historical and recent development of photovoltaic thermal (PVT) technologies. Renewable and Sustainable Energy Reviews, Volume 42, pp. 1428-1436, DOI: https://doi.org/10.1016/j.rser.2014.11.044.

Li, H., Sun, L. \& Zhang, Y., 2014. Performance investigation of a combined solar thermal heat pump heating system. Applied Thermal Engineering, 71(1), pp. 460-468, DOI: https://doi.org/10.1016/j.applthermaleng.2014.07.012.

Liu, H., Jiang, Y. \& Yao, Y., 2014. The field test and optimization of a solar assisted heat pump system for space heating in extremely cold area. Sustainable Cities and Society, Volume 13, pp. 97-104, DOI: https://doi.org/10.1016/i.scs.2014.05.002.

Longo, G., Mancin, S., Righetti, G. \& Zilio, C., 2016. HFO1234ze(E) vaporisation inside a Brazed Plate Heat Exchanger (BPHE): Comparison with HFC134a and HFO1234yf. International Journal of Refrigeration, Volume 67, pp. 125-133, DOI: https://doi.org/10.1016/j.ijrefrig.2016.04.002.

Longo, G. \& Zilio, C., 2013. Condensation of the low GWP refrigerant HFC1234yf inside a brazed plate heat exchanger. International Journal of Refrigeration, 36(2), pp. 612-621, DOI: https://doi.org/10.1016/j.ijrefrig.2012.12.018.

Martin, H., 1996. A theoretical approach to predict the performance of chevron-type plate heat exchangers. Chemical Engineering and Processing: Process Intensification, 35(4), pp. 301-310, DOI: https://doi.org/10.1016/0255-2701(95)04129-X.

Migliorini, L., Molinaroli, L., Simonetti, R. \& Manzolini, G., 2017. Development and experimental validation of a comprehensive thermoelectric dynamic model of photovoltaic modules. Solar Energy, Volume 144, pp. 489501, DOI: https://doi.org/10.1016/j.solener.2017.01.045.

NIST, 2017. REFPROP. [Online] Available at: https://www.nist.gov/srd/refprop [Accessed 1 October 2017].

Nuntaphan, A., Chansena, C. \& Kiatsiriroat, T., 2009. Performance analysis of solar water heater combined with heat pump using refrigerant mixture. Applied Energy, 86(5), pp. 748-756, DOI: https://doi.org/10.1016/i.apenergy.2008.05.014. 
Shah, M., 1979. A general correlation for heat transfer during film condensation inside pipes. International Journal of Heat and Mass Transfer, 22(4), pp. 547-556, DOI: https://doi.org/10.1016/0017-9310(79)90058-9.

SoLink, 2017. SoLink PVT. [Online] Available at: http://www.solink.it [Accessed 1 October 2017].

Zondag, H., De Vries, D., Van Helden, W. \& Van Zolingen, R., 2003. The yield of different combined PV-thermal collector designs. Solar Energy, Volume 74, pp. 253-269, DOI: https://doi.org/10.1016/S0038-092X(03)00121X. 